\title{
Canadian Model of Military Leadership as a Successful Mixture of Civilian and Military Experiences
}

doi: http://dx.doi.org/10.12775/JCRL.2015.005

\author{
Piotr MalinowsKi \\ National Defence University, Warsaw, Poland \\ e-mail: p.malinowski@aon.edu.pl
}

\begin{abstract}
The origins of military leadership are rooted in ancient times and its embodiment are great chieftains and commanders. However, since the moment when in organisation and management sciences the civil theories of leadership started to emerge, the military forces have incorporated their solutions to structure the assumptions of new, coherent and effective models of military leadership. A good example of such solutions is the Canadian model of military leadership, competently merging the civil theories with experience and needs of the military environment. This solution may be a perfect example of effective application of leadership theory to modify the existing national model of military leadership and construct a more efficient one.
\end{abstract}

Keywords: leadership; military organisation; Canadian model of military leadership.

\section{Introduction}

The issue of leadership becomes more and more solidified in a general theory of modern command and it constitutes an integral part of the dispute over its essence and nature. Simultaneously, creating optimal solutions in the scope of military leadership is a continuous process 
that the armed forces of democratic systems pay a lot of attention to. It predominantly stems from ongoing transformations of the social and military environment and new experience which the armed forces accumulate while running various military operations. Leadership importance as an area of studies and a field for developing practical solutions is also associated with the fact that leadership is deemed as a backbone facilitating the functioning of military organisations. Leadership is viewed as an important functional element of the systems that govern all management levels, referring to organisational, group (team) and individual aspects, as well as an element of education and career development included in the military educational system at all levels.

One of the components of developing Polish leadership solutions on a national scale is observation and analysis of solutions applied by other armies, especially the allies that have re-modelled their own concepts of military leadership based on multi-year experience. Therefore, the aim of the paper is to analyse Canadian solutions which may be applied in the course of improving a national military leadership model. Obviously, while developing and improving the Polish model of leadership, we need to pay attention to differences in conceptual solutions arising from national traditions, specific social transformations, as well as the local ones, and challenges our military forces need to face while participating in international operations and activities.

\section{Basic assumptions of the Canadian model of military leadership}

The transformations of the Canadian model of military leadership occurring at the beginning of this century were based on earlier solutions applied in the 1970s. As a part of the Canadian army general doctrine, it has been assumed that the success in modern armed conflicts can only be ensured by appropriate military resources, good recognition and planning of actions, sufficient forces, proper communications, but also strong leadership (CFJP-01, 2009, p. 3.4). That is why leadership is treated as an important moral factor of the Canadian military power (CFJP-01, 2009, p. 3.4), as presented in Figure 1.

In the Canadian military doctrine, it is indicated that a success in modern military conflicts is not only achieved through relevant military resources, good intelligence and planning operations, competent and 


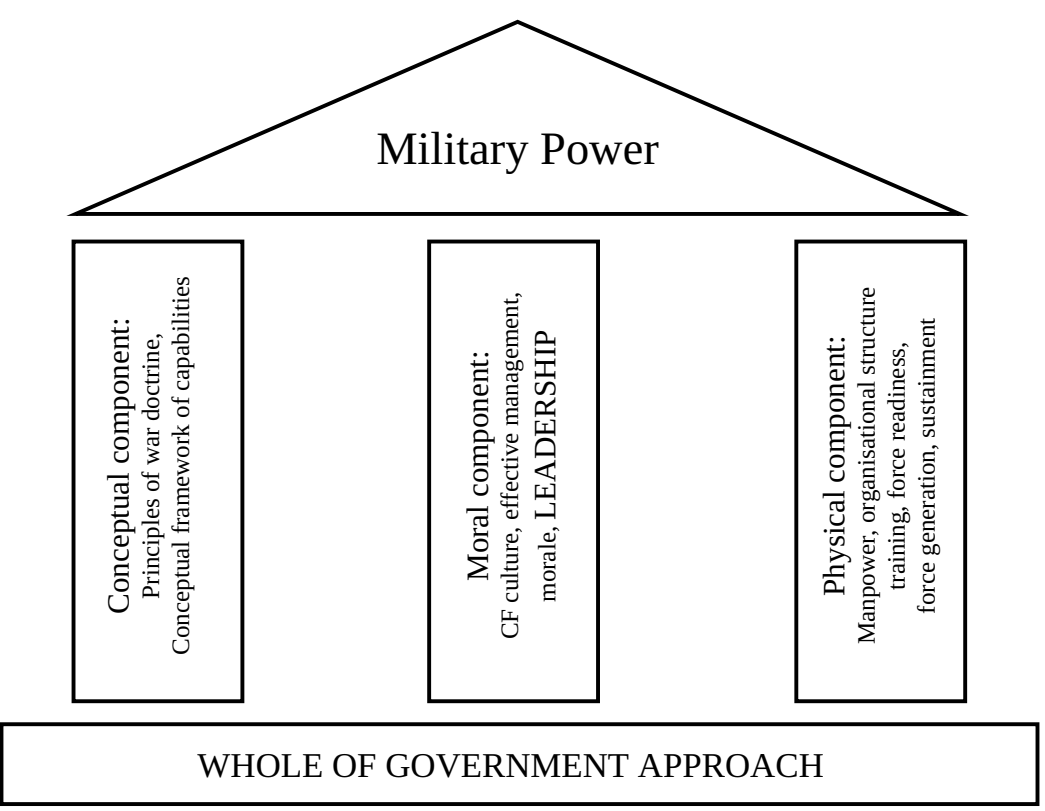

Figure 1. Leadership as an element of the Canadian military power Source: CFJP-01, 2009, p. 2.4.

capable flexible forces and proper communications, but also appropriate and strong leadership (CFJP-01, 2009, p. 3.4). In addition to individual requirements leadership competences are deemed as one of the three key factors, next to the professional body of knowledge and the war fighting skills, around which Canadian Armed Forces (CAF) general professional development system is built. The Canadian Forces Professional Development System (CFPDS) is designed to ensure that members of CAF are capable of effective leadership across the full spectrum of military service as one of core competencies that span from leading people to leading the institution.

The Canadian military forces assume a proper leadership philosophy which is not only expressed through striving to achieve a high leadership standard as a significant command requirement, but also to ensure a proper interpretation of military leadership. According to this interpretation, leadership is "directly or indirectly influencing others, by means of formal authority or personal attributes, to act in accordance with one's intent or a shared purpose" (CDA, 2005a, p. 3). Despite the fact that the 
nature of this interpretation is to be neutral, i.e. possible to be applied in a wide scope of situations, the foundation of the assumed model has been based on the assumption that finding the actual differences in the character of air, sea and land operations is necessary. According to Alan Okros (2010, p. 22), it is a basic assumption which is to ensure the maximum efficiency of a proposed military leadership model.

Simultaneously, we can take note of the need to differentiate a model of leadership depending on the level of command, since the leaders at particular levels function in different conditions that influence the manner according to which they perform their roles. In leadership at lowest and middle levels of command, i.e. at the level of groups, teams, larger subdivisions and divisions, the leaders are engaged in management and supporting others in carrying out their daily duties and defence tasks they have been assigned with. Because of the requirement to often interact face-to-face and exerting a direct influence on others, their functioning is described as leading people (CDA, 2005a, p. 6). Whereas at higher levels of command, i.e. military-strategic and national-strategic, the leaders are directly responsible for maintaining the current military capabilities and preparation of future planning, strategic and professional competences development systems necessary for the armed forces functioning. Their functioning in the applied model assumptions is described as leading institutions (CDA, 2005a, p. 6).

Another, equally important element of the assumptions applied within the model is perceiving the influence of leadership on collective efficiency, similarly to other formally-structured organisations. This problem predominantly refers to actions taken by the leaders as they are a decisive link, having the greatest impact on the complete result expressed in five areas: success of actions, internal integration, self-esteem and involvement of entire personnel and military ethos. Referring to the presented assumptions on the leadership efficiency, it is assumed that leadership in the Canadian Armed Forces is based on proper "directing, motivating, and enabling others to accomplish the mission professionally and ethically, while developing or improving capabilities that contribute to mission success" (CDA, 2005a, p. 5). Efficiency-based attitude towards the shaping of leadership from a small team to entire institution is as well aimed at achieving additional organisational results that should also be the subject of interest of leaders at every level, i.e.: creating a professional image and reputation, trust and belief in the armed forces efficiency and shaping of positive public support. 
According to the model assumptions, the functioning of leaders in the Canadian Armed Forces conditions is also related with a variable level of direct and indirect influence exerted on personnel and organisation, resulting from a given command level characteristics and the nature of both types of influence. At the same time, intermediate forms of leaders' influence, which combine the functioning based on leading people, yet with elements of leading organisations, with more emphasis on leading a military unit, are possible to occur.

What can be observed in the applied assumptions, is not only the complexity of leadership, its organisational omnipresence, but also a significant influence on the functioning of the entire military environment. In the studied model, the stress is also put on the issue of a military leader functioning in relationships with civilian personnel and within the civilian environment, being the surrounding of virtually each element of the armed forces. Attention is also paid to the ability of functioning in an environment which is often culturally diverse.

\section{Theoretical foundations of the model}

The pursuit of an effective military leadership model prompted the search for appropriate theoretical basis of the proposed assumptions and solutions. That is why the conceptions of many prominent management theoreticians have formed the basis of the Canadian leadership model. These are mostly the researchers categorised as the representatives of contingency era (Van Seters and Field, 1990, p. 35), which is known for such a significant development of variable concepts and models that it is generally viewed as a milestone in the leadership theory. The representatives of this period were the first to claim that sources of leadership cannot be found in any of the clear-cut forms of single-layered studies in the past. Sources of leadership are embedded in almost all elements, meaning that efficient leadership is not conditioned by a single factor, but a series of them, such as: behaviour, personality, influences and circumstances (Van Seters and Field, 1990, p. 35). The assumptions governing the Canadian model of leadership are generally based on the theoretical models and concepts of Fred E. Fidler, Robert J. House, Victor H. Vroom, Phillip W. Yetton, Arthur G. Jago, Paul Hersey and Kenneth H. Blanchard. 
The contingency model by Fred E. Fidler (1964), subsequently modified in 1967, is focused on dependencies between individual features of a leader and situational circumstances. It claims that an appropriate recognition of a situation and adapting an adequate leadership manner to it form the basis of leader's effectiveness. Fidler assumes that the manner of leadership is a part of a given individual's personality, and therefore it is something permanent and difficult to change. For that reason, instead of trying to come up with a new manner of leadership, it needs to be borne in mind that the leaders are not able to act efficiently in every situation. Simplifying, it may be indicated that if a leader is a likeable person, despite being responsible for the tasks of high structure or routine tasks, such person's command over situation is strong. The applied assumptions are best illustrated by the following example: a non-commissioned officer, popular among subordinates and carrying out tasks with them, despite having a high level of control over others, should be an effective leader in such specific group relationships (Schulz and Schulz, 2002, p. 246).

The path-goal theory of leader effectiveness by Robert J. House (1971), published in 1971, is associated with stimulating a leader's motivation to fulfil the indicated goals. It constitutes an extension of earlier concepts of motivational expectations. The goal path theory assumes that subordinates may be effectively motivated if actions taken by a leader derive from features of subordinates and tasks. The assumptions applied in this theory indicate that an effective leader will be a person who, due to a flexibly applied manner, reflects in proper behaviour, provides the subordinates with a satisfactory explanation of methods (paths) of achieving goals, presents personal gains, ensures support and aids in tackling the emergent obstacles. Particular types of behaviour exemplified in R.J. House's theory are effective in given conditions, which has been also confirmed by other researchers. Most of the opinions confirm that the theory is logically and empirically grounded to a sufficient extent and it is simultaneously a theory which significantly extends the scientific horizons and adequately indicates the assumptions governing the manner of leader functioning.

Normative Decision Model created by Victor H. Vroom and Phillip W. Yetton (1973) as well as Victor H. Vroom and Arthur G. Jago (1988) is to support one of the aspects of leadership consisting of the choice of the decision making method that would be the best fit for the essence of the considered issue. However, the original model by Vroom and 
Yetton has not been fully developed and upon conducting new research V.H. Vroom, this time with A. Jago, modified it. However, the discussed model brought reliable data on situational factors which need to be considered while choosing the manner of leadership and the degree of participation in a particular, complex situation. The indisputable benefit of the model is the confirmation, similarly as in the case of R.J. House's solution, that leadership behaviour is not constant and can be influenced by a situation a leader is engaged in. The solutions proposed in the model, in addition to indicating the effective behaviour of a leader in the decision making process, may also be used to develop the ability of situation assessment in which a leader may function and to improve the level of sensitivity to selected aspects within environment.

Among contingency theories, the situational leadership theory had the greatest impact on the final shape of the Canadian leadership model. Developed by Paul Hersey and Kenneth H. Blanchard in 1969, originally called the life cycle theory of leadership (Hersey and Blanchard, 1969), subsequently modified in 1977, it was finally called Situational Leadership II (SLII ${ }^{\circledR}$ ) in 1985. This concept does not only constitute the basis for Canadian military leadership model assumptions, but it is also one of the most important elements taught in Royal Military College (English (Ed.), 2006, p. 23).

The situational leadership theory is focused around the assumption that effective leaders adapt their leadership manners to the degree their potential followers are prepared to achieve the satisfactory results within given time frames (situation). The primary idea underlying the situational leadership theory is the fact that there is only one, best manner of leadership. According to this theory, the greatest successes are cherished by those leaders who adapt their manner of actions to the level of psychological and functional maturity of particular individuals or groups that they try to influence or lead. Effective leadership is not only dependant on people or groups that are influenced by their leader, but also on the tasks, responsibilities and functions to be carried out. The starting point of this theory is the assumed taxonomy of four manners of leadership. These manners depend on the intensity of directive and supportive behaviours of a leader, varying as to the methods of conveying instructions (guidelines), supporting individuals and distribution of responsibilities and four stages of co-workers maturity associated with them. Different manners of leadership actions, dependent on the stage of maturity of individuals under leadership correspond to the behaviour 
concentrated on (Blanchard, 2007, pp. 77-80): directing, coaching, supporting and delegating.

Nevertheless, achieving high leadership efficiency, as rightly claimed by Blanchard (2007, p. 163), "requires a leader who is able to cope with the transition from dependency to co-dependency". The author associates determining the optimal manner of leadership with diagnosing a level of co-workers development, their efficiency and motivation. Choosing a manner is also dictated by the approach taken with regards to the problem of stimulating progress and keeping high effectiveness. It may be indicated that leading according to the situational leadership theory is associated with interactions and effects of influence in the course of striving to fulfil organisational goals, as well as to satisfy individual and group aspirations. Such understanding of leadership is accurately reflected in the phrase claiming that "a man starts to lead at a high level only when he realizes that leadership does not only apply to him” (Blanchard, 2007, p. 158).

This theory, despite the fact that most of the researchers deem it as imperfect, has many benefits, the biggest ones being its practical value and clarity of assumptions. The prepared SLII ${ }^{\circledR}$ model is widely used because its intuitive nature, ease of implementation and considerable amount of publications and clarifying-demonstrative materials attract many followers.

In the Canadian leadership model the attitude presented by John P. Kotter (2012, p. 39) can also be found. He stresses that: "at times of war the competent leaders are necessary at each level. Nobody has ever been brilliant enough to figure out a way of effective management of soldiers at battlefield. There, they need to be led".

Some of the assumptions seem converge with the ideas of James M. Kouzes and Barry Z. Posner (2010), indicating that leadership is an art of evoking in people the desire to take actions aiming at meeting common aspirations, since leadership is not about personality, but about behaviour. Thus, a leader needs to "learn how to be flexible with regards to leadership manner while keeping strictly in line with the rules" (Kouzes and Posner, 2010, p. 47) as leadership requires especially reasonable contact with others on emotional level. Therefore, the most welcomed traits ascribed to the leaders are (Kouzes and Posner, 2010, p. 26): honesty, ability to inspire others, farsightedness and being competent. The Canadian solutions are also based on the results of over twenty-year-long studies conducted by James M. Kouzes and Barry 
Z. Posner (2010, p. 106), which clearly indicate that each skill can be enhanced, trained or improved upon if a leader is motivated, eager and has an opportunity to train and ability to obtain preliminary guidelines and feedback. Whereas the key to the highest effectiveness within an organisation are not only good leaders but also good leadership (Kouzes, Posner, 2010, p. 110), meaning that one of the aspects of the tasks carried out to improve organisational effectiveness is focusing on the process of leadership, not only on the leader person and development of his competences and behaviour.

What is also important for the final shape of the Canadian model are the views presented in the mid 1980s by Edgar H. Schein (2004, p. 10), who indicates that leadership needs to be considered in conjunction with organisational culture, as two sides of the same coin, since a leader firstly shapes culture and then creates a group or an organisation. According to these ideas, leadership shapes and modifies culture and management and administration is effected within particular organisational structure (Schein, 2004, p. 11).

Some of the Canadian model assumptions are also based on the relationship between a leader and his followers, supported by James MacGregor Burns (1978), the basis of which is co-interaction resulting from the same or at least approximated goals. In these assumptions, one can find the influence of views of Stephen J. Zaccaro, who analyzes the traits constituting the permanent leader characteristics, as well as of Burt Nanus (2007), deemed as the creator of the visionary leadership theory that is to explain how some of the leaders attract their followers and inspire them to achieve same goal and achievements exceeding the ordinary expectations. In his interpretation of leadership he indicates that "effective leadership gives strength to an organisation to maximize its influence of well-being of its members and this part of society it belongs to" (Nanus, 2007, p. 31). The Canadian model does also contain a reference to national conception - Ten Management Roles, developed by Henry Mintzberg (1989).

\section{Analysis of the detailed solutions within the model}

The currently presented assumptions within the Canadian model of leadership are a result from the update which was completed in 2003 in the Canadian Forces Leadership Institute (CFLI). The impulse initiating 
the change in views upon the military leadership in the Canadian army was the incident which happened during the operations of Canadian soldiers in Somalia in March 1993 (Horn and MacIntyre, 2010, p. 32) and the discussion it prompted among the military ranks. As a result, the decision was made to establish, in February 2001, the Canadian Forces Leadership Institute in the Canadian Defence Academy.

A reflection of assumptions and interpretation of leadership is its concept based on four main values, presented in Figure 2, which substantially influence the armed forces functioning.

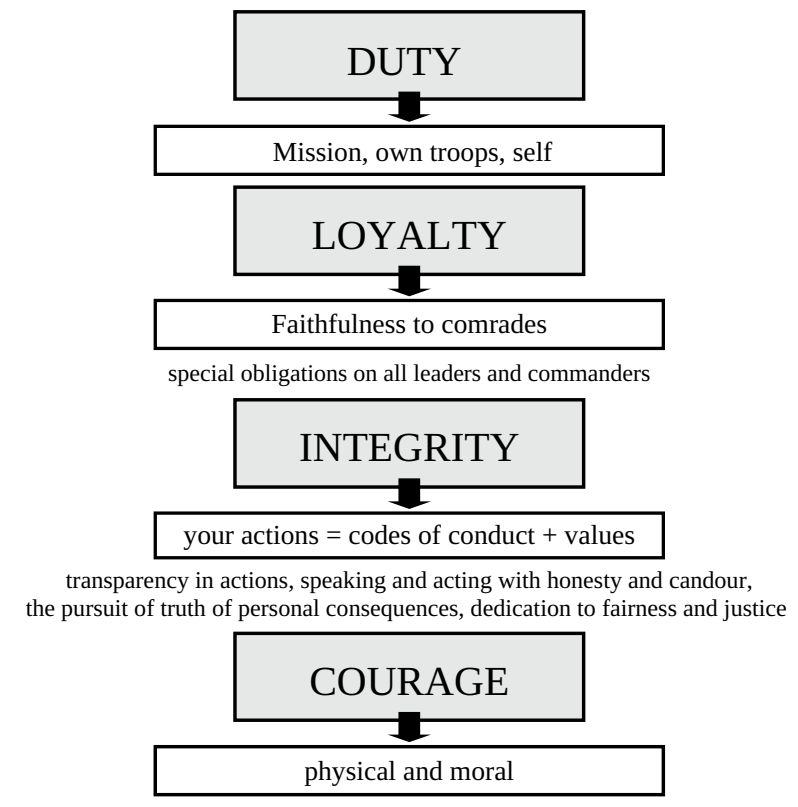

Figure 2. Basic values of the Canadian Forces

Source: own study based on CDA, 2003, pp. 16-19.

Trust is an important element influencing leadership concept in the Canadian Army, it simultaneously establishes and maintains healthy relations with subordinates, co-workers and superiors (CDA, 2005a, p. 5). Its positive influence is associated with actions taken by an individual and group effectiveness, endurance in face of adversities, ability to react to stress, job satisfaction and engagement in further duty. Creating the atmosphere of trust between the leaders and the led individuals is 
also positively related with such features of a good soldier as honesty, fair conduct and willingness to cooperate.

The Canadian concept also adopted a simplified leadership model based on systemic approach (CDA, 2005a, p. 17). It consists of series of dependencies between various factors influencing the functioning and interaction of a leader. These are four main groups of variables: features and behaviour of a leader, individual and group factors, situational factors and the achieved effects. Such is the basis of general structure of this model as presented in Figure 3.

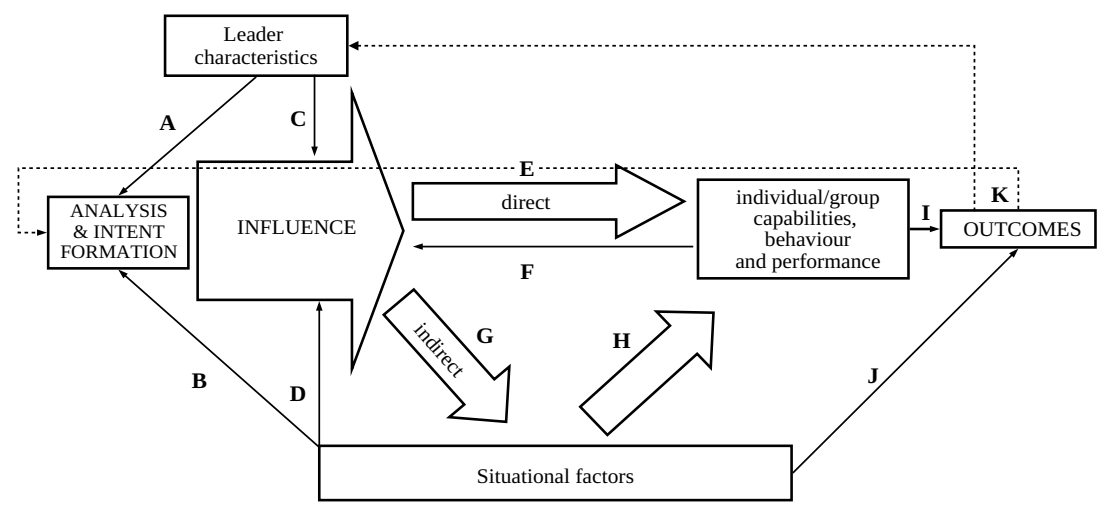

Figure 3. Simplified Canadian Forces leadership model Source: CDA, 2005a, p. 17.

The individual assumed dependencies (relationships) (CDA, 2005a, pp. 17-19) associated with the influence of basic factors mean:

- A - dependency derived from the level of leader employment (tactical or strategic) and source of power (technical, cognitive, social skills or other) and the influence on the conducted analyses, decisions and plans;

- B - dependency derived from the influence of situational factors on the performer analyses and effected intentions, resulting from the awareness of a leader of his scope of responsibilities, way of thinking, decision making and imagination - may shape and drive a leader's behaviour;

- C and D - these dependencies are the essence of leadership since they influence the form of intention and may decrease or 
increase the influence stemming from a leader's characteristics or situational factors;

- E - dependency indicating a direct influence of a leader exerted on the modification of individual or group abilities, behaviour and effectiveness;

- F - dependency derived from active or reactive influence of individuals under leadership;

- G - dependency manifesting an intermediate influence of a leader on the shape of tasks, group, system, institution or environment characteristics;

- $\mathrm{H}$ - dependency indicating an intermediate interaction of a leader, modifying individual or group skills, behaviour and effectiveness, resulting from such substitutes as procedures, standards or technologies;

- I and J - dependencies indicating an independent or joint influence of the performers and systems on the result of initiated interaction;

- $\mathrm{K}$ - dependency indicating the influence of results on further perception of effectiveness and leader's behaviour.

In the presented model, according to the assumptions of the Canadian concept, effective leadership is to be ensured by proper leader characteristics encompassing: knowledge and skills; cognitive abilities; social skills; individual traits; and professional motivation and system of values.

Obtaining an effective interaction of a leader is, according to the creators of the leadership model, associated with appropriate behaviour which may be shaped as presented in Figure 4.

This behaviour is organised depending on the level of control preferred by a leader. Especially emphasized are its forms that are most often chosen by a transformative leader, currently deemed as a significant model of behaviour, appreciated due to skilful handling of most difficult challenges and dynamics of organisational surrounding posing a serious threat, not only for an organisation, but also for a leader himself and his followers.

In the Canadian leadership concept the sources of power (CDA, 2005b, p. 59) at leader's disposal are also esteemed and distinguished from a formal scope of power held by a leader, simultaneously indicating that a success of actions is the result of both of these factors interacting. It also stresses the aspect of non-constant and changeable nature 


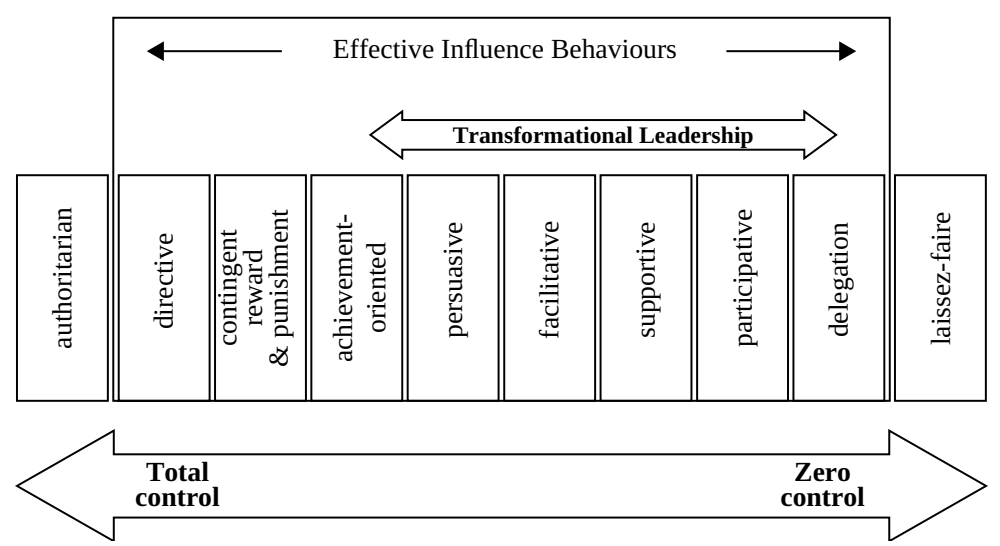

Figure 4. Leader's behaviour influencing interaction effectiveness

Source: CDA, 2005a, p. 21.

of formal power, resulting from changes of posts and promotions, as well as the need to pay attention to one's own non-formal authority, also the one that has not been permanently ascribed to a given individual.

Thus the special attention is paid to, similarly as in most leadership theories, the meaning of dynamic relations between a leader, followers and a situation, fuelling or quenching the power of held authority with variable intensity. What is also emphasized as crucial in modern leadership, is the importance of ethical behaviour of a leader which is to be founded on basic values and be uniform in character, not only limiting to professional work ethics, but also stretching out to so-called nine to five ethics (CDA, 2007a, p. 15)

Due to the changes in structures and new tasks to be faced by the military forces, more and more attention in leadership concepts is paid to the functioning of a leader in various teams at each organisational level. Whereas at the levels of command, where there is the need to cooperate between non-commissioned and commissioned officers, the element of leadership that is highly stressed in the Canadian Army is a relation between a commander and a senior non-commissioned officer, ensuring the creation of proper image and leadership level (Banks, 2006, p. 3). The need to pass on knowledge and experience among non-coms and officers is also crucial to intensify the engagement in achieving the goal of tasks (English, 2006, p. 48) and more effective leadership. 
Experience from modern conflicts indicates that significance of non-commissioned officers has increased, not only in the scope of direct leaders at various levels, but also as leaders whose actions may influence the achievement of goals at a considerably higher level, the strategic one included (English, 2006, p. 48). That is why, in accordance with the Canadian model, preparation of non-coms should exceed the previous scope of leadership skills, especially with reference to noncoms at higher chains of command.

As conclusions from the performed studies indicate, leadership environment is becoming more ambiguous and the scope of leader functioning becomes more complex along with appointing for higher posts and extending the scope of responsibilities. It is influenced by the system of preparing individuals to perform the function of a leader applied in Canadian solutions. The applied assumptions of the solution called Leader Development Framework assume four levels of leadership skills necessary to perform the role of a leader at various organisational levels, as presented in Figure 5.

\begin{tabular}{|c|c|c|c|c|c|}
\hline Leader levels & EXPERTISE & $\begin{array}{l}\text { COGNITIVE } \\
\text { CAPACITIES }\end{array}$ & $\begin{array}{c}\text { SOCIAL } \\
\text { CAPACITIES }\end{array}$ & $\begin{array}{c}\text { CHANGE } \\
\text { CAPACITIES }\end{array}$ & $\begin{array}{l}\text { PROFESSIONAL } \\
\text { IDEOLOGY }\end{array}$ \\
\hline SENIOR & STRATEGIC & $\begin{array}{l}\text { CREATIVE } \\
\text { ABSTRACT }\end{array}$ & $\begin{array}{c}\text { INTER- } \\
\text { INSTITUTIONAL }\end{array}$ & $\begin{array}{l}\text { PARADIGM } \\
\text { SHIFTING }\end{array}$ & STEWARDSHIP \\
\hline ADVANCED & & & & & \\
\hline INTERMEDIAT & & & & & \\
\hline JUNIOR & TACTICAL & ANALYTICAL & $\begin{array}{l}\text { INTER- } \\
\text { PERSONAL }\end{array}$ & OPEN & INTERNALIZE \\
\hline
\end{tabular}

Figure 5. Framework model of leader development Source: CDA, 2007b, p. 150.

To achieve particular levels, the candidates for leaders need to present a variable set of skills in five areas and sixteen features (attributes) associated with them, provided in the descriptive part of the model (Edwards et al., 2006, p. 10). The areas of capabilities, treated as metacompetences (Horn and Walker, 2008, p. 11) and consistent with presented leader's characteristics are the following (CDA, 2007b, p. 130): 
- expertise, including technical and specialist skills;

- cognitive abilities, including analytic skills, ability to make decisions, creativity;

- social skills, including flexibility, interpersonal, team and communicative skills;

- ability to change, including self-development, ability to form a group, ability to learn and build a learning organisation;

- professional ideology, i.e. acquiring ethos, moral reasoning, reliability.

A significant element of the Canadian solution assumptions are the effective strategies of education and teaching. They have emerged, as the entire modern leadership concept in the Canadian army, on the verge of the centuries.

\section{Summary}

The model of leadership and leading implemented in the Canadian Forces is a highly extensive solution and its assumptions pertain to numerous aspects of leaders' functioning at all organisational levels. It is dictated by the assumption stressed by Allan English (2008, p. I) stating that "the interconnectedness of leadership and command is such that leadership is an essential role requirement for commanders". The solutions that seem useful in the process of modifying the Polish military leadership model include: accurately-defined leadership levels and leadership skill sets required at particular levels, as well as a coherent framework model of military leaders development.

The Canadian Forces still conduct intensive studies and are engaged in a wide scope of cooperation with civilian environment and, through collecting experience and exchange of opinions, improve upon and reorganize the system of educating candidates for leader roles, using a series of solutions proposed by many theories and concepts of leadership and also refer to experience from various peacekeeping and stabilisation operations.

The needs for improving the military leadership model have been discussed in the Canadian Forces over recent years. It is associated with the role that the military leaders performed in counter-insurgency operations and the concept of Canadian comprehensive approach called the Whole Government (WoG) approach (Wentzell, 2012, p. 
38), i.e. an approach assumed with regard to civilian and military issues that came into view in such operations in Afghanistan. However, the opinions expressed by various authors are ambiguous and therefore, these theories have not been applied to the Canadian model of military leadership yet. Nevertheless, the conclusions drawn from the cooperation of Canadian Forces with government offices during the operations in the Afghan district of Kandahar (Meyerle et al., pp. 151-160) constitute the materials that should be considered while modifying the national military leadership model, similar to the Polish experience from Ghazni.

Such an approach towards shaping the leadership model in military environment may be seen as a very interesting solution. It is one of the most valuable and coherent ones among all the NATO members and is worth to be considered while national solutions are being modified or developed. The modified Polish model of military leadership, similarly as in the case of the Canadian Forces, should be based not only on theoretical solutions adapted from other armies, but also on valuable experiences and conclusions drawn from the operations conducted in Afghanistan and Iraq.

\section{References}

Banks, D. (2006), “Reflections of Operational Service”, in: Horn, B. (Ed.), In Harm's Way. On the Front Lines of Leadership: Sub-Unit Command on Operations, Canadian Defence Academy Press, Kingston, pp. 1-16.

Burns, J.M., (1978), Leadership, Harper Collins, New York.

Blanchard, K. (2007), Przywództwo wyższego stopnia, PWN, Warszawa.

CAF (2013), Canadian Armed Forces Professional Development. Retrieved from http:// www.forces.gc.ca/en/training-prof-dev/index.page (accessed 4 February 2015).

CDA (2003), Summary of Duty with Honour: The Profession of Arms in Canada, Canadian Defence Academy, Kingston. Retrieved from http://publications.gc.ca/collections/collection_2011/dn-nd/D2-150-2003-1-eng.pdf (accessed 30 April 2015).

CDA (2005a), Leadership in the Canadian Forces: Doctrine, Canadian Defence Academy, Kingston. Retrieved from http://publications.gc.ca/collections/collection_2013/ dn-nd/D2-313-1-2005-eng.pdf (accessed 30 April 2015).

CDA (2005b), Leadership in the Canadian Forces: Conceptual Foundations, Canadian Defence Academy, Kingston. Retrieved from http://publications.gc.ca/collections/ collection_2013/dn-nd/D2-313-2-2005-eng.pdf (accessed 30 April 2015).

CDA (2007a), Leadership in the Canadian Forces: Leading People, Canadian Defence Academy, Kingston. Retrieved from http://publications.gc.ca/collections/collection_2013/dn-nd/D2-313-3-2007-eng.pdf (accessed 30 April 2015).

CDA (2007b), Leadership in the Canadian Forces: Leading the Institution, Canadian 
Defence Academy, Kingston. Retrieved from http://publications.gc.ca/collections/ collection_2013/dn-nd/D2-313-5-2007-eng.pdf (accessed 30 April 2015).

CFJP-01 (2009), Canadian Military Doctrine, Canadian Forces Experimentation Centre, Ottawa. Retrieved from http://publications.gc.ca/collections/collection_2010/forces/ D2-252-2009-eng.pdf (accessed 30 April 2015).

Edwards, R.S., Bentley, L.W., Walker, R.W. (2006), "Professionalism and Leadership: Requisite Proficiencies for CF Transformation”, Canadian Military Journal, Spring, pp. 6-12. Retrieved from http://www.journal.forces.gc.ca/vo7/no1/doc/transfor-eng. pdf (accessed 30 April 2015).

English, A. (2008), Command and Control of Canadian Aerospace Forces: Conceptual Foundations, Canadian Forces Aerospace Warfare Centre Production Section, Trenton. Retrieved from http://airforceapp.forces.gc.ca/CFAWC/eLibrary/pubs/ C2_Conceptual_Foundations.pdf (accessed 30 April 2015).

English, A. (Ed.) (2006), The Operational Art: Leadership and Command, Canadian Defence Academy, Kingston.

English, A. (2006), “The Senior NCO Corps and Professionalism: Where do we Stand?”, in: McIntyre, A., Davis, K.D. (Eds.), Dimensions of Military Leadership, Canadian Defence Academy Press, Kingston.

Fiedler, F.E. (1964), “A Theory of Leadership Effectiveness”, in: Berkowitz, L. (Ed.), Advances in Experimental Social Psychology, Academic Press, New York.

Hersey, P., Blanchard, K.H. (1969), “Life Cycle Theory of Leadership”, Training and Development Journal, Vol. 23, Issue 5, pp. 26-34.

Horn, B., MacIntyre, A. (Eds.) (2010), In Pursuit of Excellence: International Perspective of Military Leadership, Canadian Defence Academy, Kingston.

Horn, B., Walker, R.W. (Eds.) (2008), The Military Leadership Handbook, Dundurn Press and Canadian Defence Academy Press, Ottawa.

House, R.J., (1971), “A Path-Goal Theory of Leadership Effectiveness”, Administrative Science Quarterly, Vol. 16, pp. 321-339.

Kotter, J.P. (2012), Co właściwie robiq przywódcy? in: O przywództwie: 10 Idei HBR, Warszawa, ICAN Institute.

Kouzes, J.M., Posner, B.Z. (2010), Przywództwo i jego wyzwania, Uniwersytet Jagielloński, Kraków.

Meyerle, J., Katt, M., Gavrilis, J. (2010), Counterinsurgency on the Ground in Afghanistan: How Different Units Adapted to Local Conditions, CNA Analyses \& Solutions, Alexandria. Retrieved from http://www.dtic.mil/dtic/tr/fulltext/u2/a533649.pdf (accessed 27 October 2015).

Mintzberg, H. (1989), Mintzberg on Management: Inside our Strange World of Organisations, Free Press, New York.

Nanus, B. (2007), Wizjonerskie przywództwo, Centrum Kreowania Liderów, Żyrardów.

Okros, A. (2010), Leadership in the Canadian Military Context, Canadian Defence Academy, Kingston. Retrieved from http://www.defence.gov.au/ADC/Docs/ CDLE/CDLE_120329_OkrosA2010LeadershipintheCanadianMilitaryContext.pdf (accessed 30 April 2015).

Schein, E.H. (2004), Organizational Culture and Leadership, Wiley \& Sons, San Francisco.

Schulz, D.P., Schulz, S.E. (2002), Psychologia a wyzwania dzisiejszej pracy, Wydawnictwo Naukowe PWN, Warszawa. 


\section{Piotr Malinowski}

Van Seters, D.A., Field, R.H.G. (1990), “The Evolution of Leadership Theory”, Journal of Organisational Change Management, Vol. 3, Issue 3, pp. 29-45.

Vroom, V.H., Yetton, P.W. (1973), Leadership and Decision-Making, University of Pittsburgh Press, Pittsburgh.

Vroom, V.H., Jago, A.G. (1988), The New Leadership: Managing Participation in Organizations, Prentice Hall, Upper Saddle River.

Wentzell, T.D. (2012), "Security Sector Reform in Afghanistan: From the Bonn Agreement to the Afghanistan Compact”, Canadian Army Journal, Vol. 14.1, pp. 31-43. 